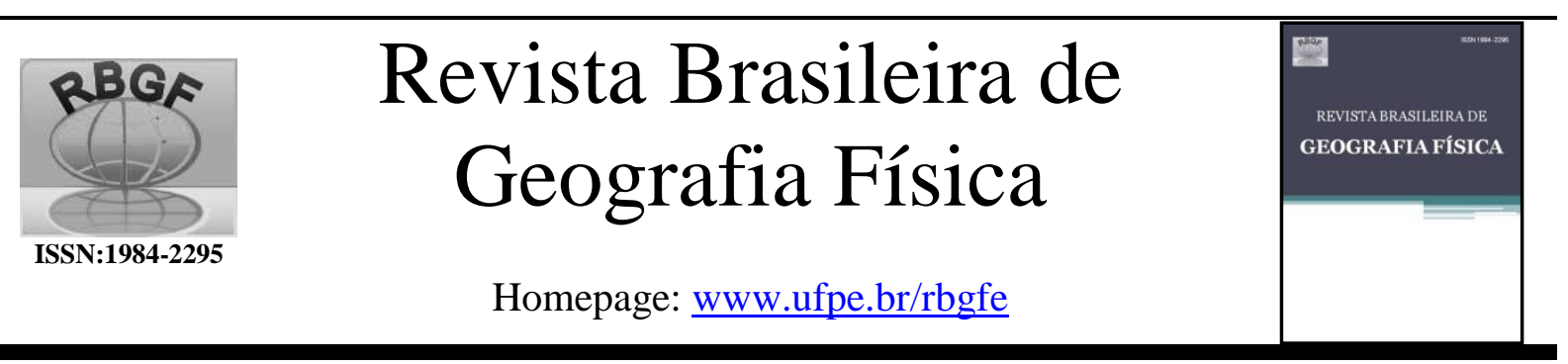

\title{
Controle Estrutural e Neotectônica na Dissecação do Relevo em Mares de Morros no Sudeste Brasileiro
}

Rafael Gomes Siqueira, Universidade Federal de Viçosa, e-mail: rafael.geo.siqueira@gmail.com, José João Lelis Leal de Souza, Universidade Federal de Viçosa, e-mail: jjlelis@gmail.com, André Luiz Lopes de Faria, Universidade Federal de Viçosa, e-mail: andre@ ufv.br, Elpídio Inácio Fernandes Filho, Universidade Federal de Viçosa. E-mail: elpidio@ufv.br

Artigo recebido em 27/10/2017 e aceite em 20/03/2018

\begin{abstract}
R E S U M O
A ação neotectônica afeta o perfil de equilíbrio dos rios, alterando a energia dos canais e influenciando diretamente no seu potencial de dissecação. Nesta pesquisa objetivou-se avaliar o controle estrutural, condicionado pelo regime climático úmido, na dissecação do relevo da bacia hidrográfica do rio Glória, Minas Gerais. A área de pesquisa localiza-se em uma região de importantes dobramentos, falhamentos e escarpas para a paisagem tectônica do Brasil Oriental, com litologia caracterizada por complexos metamórficos e suítes intrusivas. A análise foi realizada com a aplicação de parâmetros morfométricos, tendo como suporte os Sistemas de Informação Geográfica. A relação de bifurcação, o Índice de Concentração da Rugosidade e o Índice Stream Lenght-Gradient permitiram identificar o controle estrutural sobre os cursos fluviais e alta rugosidade do relevo, atribuído à reativação estrutural de falhas Meso-Cenozoicas sobre as litoestruturas do Pré-Cambriano. Esses parâmetros também indicaram diferenças com áreas de história tectônica similar em clima mais seco, evidenciando o condicionante climático sobre a rede de drenagem e a estrutura. A aplicação dos parâmetros morfométricos a partir de técnicas e procedimentos em ambiente SIG mostrou-se eficiente para detectar as influências estruturais e climáticas na conformação do relevo, com potencial para aplicação no planejamento territorial de bacias hidrográficas.

Palavras chave: relação de bifurcação; Índice de Concentração da Rugosidade; Índice Stream Lenght-Gradient.
\end{abstract}

\section{Structural Control and Neotectonic in the River Dissection of the Relief of "Seas of Hills", in Southeastern Brazil}

\begin{abstract}
A B S T R A C T
Tectonic phenomena affect the balance of river profile, changing the energy of channels and influencing the potential for dissection. This research aimed to evaluate structural control, conditioned by humid climate regime, on dissection of the watershed rio Glória relief, Minas Gerais. The area is located in a folding and faulting neotectonics landscape of eastern Brazil, with lithology characterized by complex metamorphic and intrusive suites. Morphometric parameters data were used, supported by the Geographic Information Systems. Bifurcation ratio, Concentration Index Roughness and Stream Lenght Index Gradient have identified control of the reactivation of Meso-Cenozoic faults on Precambrian rocks, with the presence of major tectonic anomalies in river courses and high roughness relief. These parameters also indicated differences with areas of similar tectonic history in drier climate, evidencing the climatic condition of the drainage network and structure. The application of morphometric parameters from techniques and procedures in a GIS environment proved to be efficient to detect structural and climatic influences in relief conformation, with potential for application in the territorial planning watershed. Keywords: Bifurcation Ratio; Concentration Index Roughness; Stream Lenght Index Gradient.
\end{abstract}

\section{Introdução}

Os canais fluviais representam o principal agente geomorfológico da superfície terrestre, drenando 68\% dos continentes (Novo, 2010). A dinâmica fluvial é responsável pelos processos de remoção, transporte e deposição dos sedimentos (Huggett, 2007; Wohl, 2014), sendo que o balanceamento entre estes mecanismos fornece a manutenção do equilíbrio fluvial. 
Os fenômenos tectônicos afetam diretamente o perfil de equilíbrio dos rios. Estas interferências se expressam de diferentes maneiras na paisagem, seja pela presença de rupturas de declive no canal fluvial, também chamados de knickpoints, ou pelo aumento da dissecação dos vales devido ao acréscimo do potencial energético dos rios.

A neotectônica do Sudeste brasileiro se desenvolve do Terciário Superior ao Quaternário, num quadro de tensões compressivas, sucedendo ao período de distensão crustal generalizada que conduziu à fragmentação do megacontinente Gondwana (Saad et al., 2005). Consequentemente, porções do litoral brasileiro foram afetados por deformações tectônicas cenozoicas que reativaram linhas de fraqueza crustais herdadas de eras geológicas anteriores (Saad, 1993), e provocaram mudanças na configuração topográfica do território brasileiro.

Recentemente, um número considerável de trabalhos sobre a dinâmica morfológica do Escudo brasileiro oriental vêm sendo produzidos (Vervloet, 2009; Couto et al., 2013; Fonseca, 2014; Celarino e Ladeira, 2014), principalmente com base na utilização de técnicas de geoprocessamento e na aplicação de análises morfométricas de bacias hidrográficas. Entretanto, ainda é divergente entre a comunidade científica a extensão da influência dos processos tectônicos na dinâmica fluvial e morfológica dos terrenos granito-gnáissicos da costa brasileira. Não obstante a isto, torna-se cada vez mais necessária a identificação de áreas com tectônica ativa ou recente, onde os processos erosivos são mais atuantes. Este tipo de informação fornece subsídios para um melhor ordenamento territorial das bacias hidrográficas, sendo útil para a adaptação das atividades antrópicas aos níveis de instabilidade natural destas áreas.

A bacia hidrográfica do rio Glória (BHRG) localiza-se no estado de Minas Gerais, em uma das áreas mais declivosas do território brasileiro, com diversos dobramentos, falhamentos e escarpas (Vieira e Gramani, 2015), configurando-se em uma área modelo de relevância para o estudo aqui proposto. O relevo da área possui trechos planos e contínuos, enquanto outros são mais irregulares $\mathrm{e}$ heterogêneos. A litologia, clima e vegetação representam, de forma geral, as áreas escarpadas no Sudeste brasileiro.
Desta forma, nesta pesquisa objetivouse avaliar o controle estrutural, condicionado pelo regime climático úmido, na dissecação do relevo da bacia hidrográfica do rio Glória, a partir de técnicas de geoprocessamento e parâmetros morfométricos elaborados em ambiente de Sistemas de Informações Geográficas (SIG).

\section{Material e métodos}

Área de Estudo

Localizada na mesorregião da Zona da Mata do estado de Minas Gerais, a BHRG possui 1.097,14 $\mathrm{km}^{2}$ de área (Figura 1a) e pertence à bacia hidrográfica do rio Paraíba do Sul. Na BHRG são englobados os municípios de Fervedouro, São Francisco do Glória, Miradouro e Vieiras, além de parte do município de Muriaé. A precipitação média anual varia em torno de 1.200 a $1.500 \mathrm{~mm}$, principalmente concentrada entre os meses de outubro e dezembro. A temperatura média anual varia de $23^{\circ} \mathrm{C}$, na porção mais baixa da bacia, a $18^{\circ} \mathrm{C}$, na região serrana onde se localiza a nascente do rio Glória (SEMAD, 2007).

A altitude varia entre $180 \mathrm{~m}$ no vale do rio Glória e $1.990 \mathrm{~m}$ nas áreas mais elevadas, associadas a rochas mais resistentes ao intemperismo e/ou, controle estrutural. A BHRG localiza-se no domínio Morfoclimático dos Mares de Morros, caracterizado por áreas mamelonares tropical-atlânticas florestadas (Ab'saber, 2003). Porém, devido à intensa pressão exercida pelas atividades agrossilvipastoris, atualmente apenas $15 \%$ da área total da bacia é ocupada por vegetação nativa (SEMAD, 2009).

A BHRG pertence à Província Geotectônica Mantiqueira Setentrional, mais especificamente a Faixa de Dobramentos Sudeste ou Faixa Atlântica (Pires, 1998). De idade transamazônica, com 2.200-1.800 G.a., a Província da Mantiqueira sofreu complexo retrabalhamento durante o Neoproterozóico pelo Ciclo Brasiliano. Esta província é integrada por uma sucessão de cinturões do tipo empurrão dobrados e controlados por distintos sistemas transpressivos de cavalgamento em direção às margens cratônicas, com orientação NNE-SSO ao longo da costa atlântica (Delgado et al., 2003). 


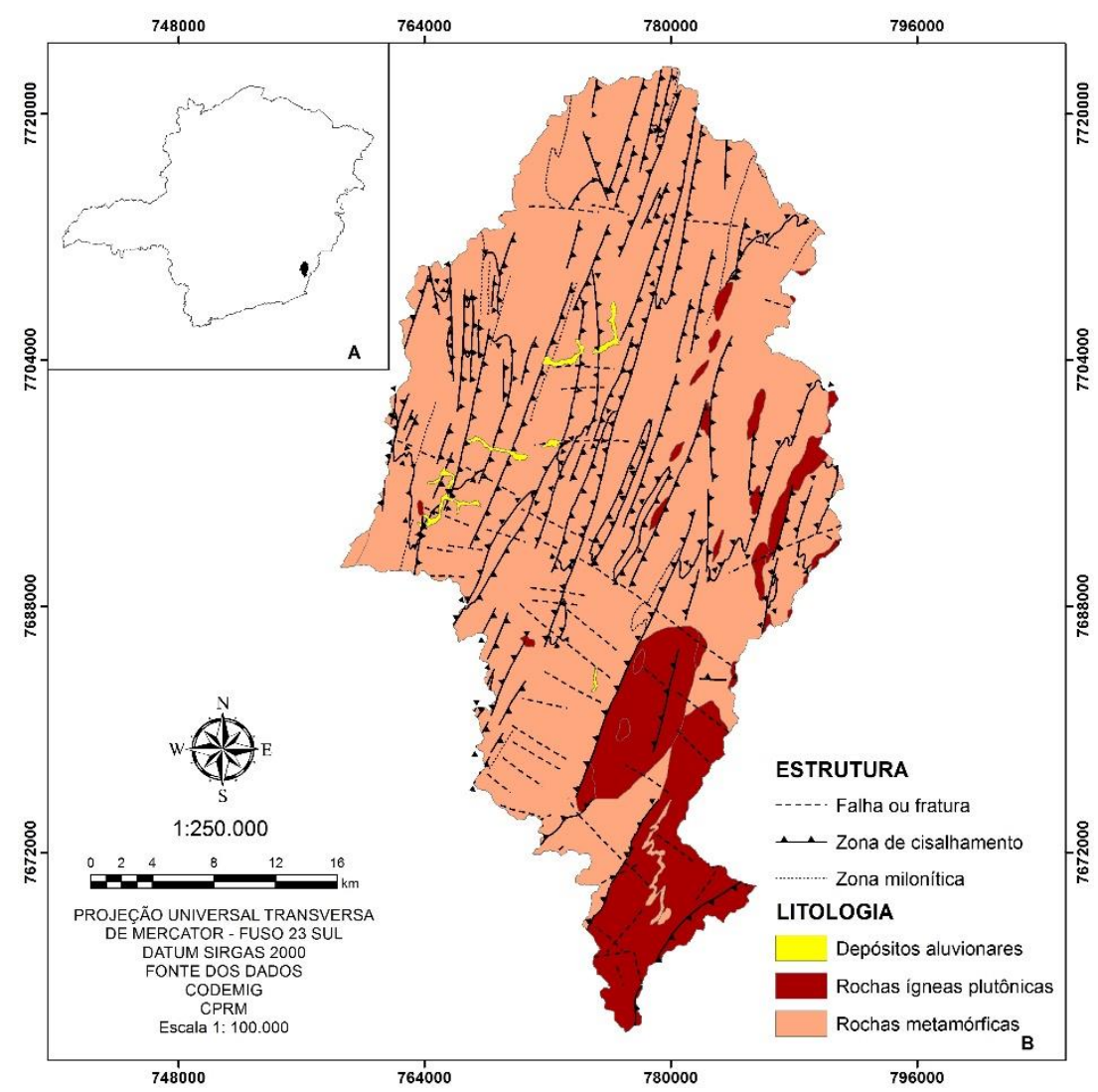

Figura 1. (a) Localização da bacia hidrográfica do rio Glória; (b) Geologia da área de estudo.

Durante a separação mesozoica, que subdividiu o megacontinente Gondwana e culminou na abertura do Oceano Atlântico, estas falhas foram reativadas em pulsos descontínuos que perduraram desde o Cretáceo até os dias atuais (Almeida e Carneiro, 1998). A reativação Wealdiana incluiu importantes movimentações tectônicas, que foram determinantes para a fisionomia atual dos falhamentos já existentes desde o PréCambriano (Vieira e Gramani, 2015).

O embasamento geológico da BHRG é caracterizado por rochas metamórficas com grau de metamorfismo de intensidade média a alta, como gnaisses e charnoquitos. Também é composto de corpos ígneos plutônicos graníticos e/ou granitóides, seccionados por zonas de cisalhamento transcorrente $\mathrm{e}$ contracional com vergência NNE-SSO, falhas transversais e zonas miloníticas (CODEMIG, 2013) (Figura 1b).

A BHRG tem quase toda sua área inclusa na unidade geomorfológica Serranias da Zona da Mata Mineira, composta por cristas e linhas de cumeada (RADAM BRASIL, 1983). A unidade é marcada pela topografia elevada, escarpas íngremes adaptadas a falhas, sulcos estruturais, grandes linhas de cumeadas e cristas alinhadas, que indicam a direção dos dobramentos e falhamentos ocorridos na área. As feições desta unidade estão associadas na área de pesquisa, principalmente aos embasamentos metamórficos do Complexo Juiz de Fora. Esse complexo corresponde a uma intercalação tectônica entre as litologias do embasamento Pré-Cambriano e os metassedimentos neoproterozóicos da Megassequência Andrelândia, ambos metamorfizados em fácies de granulitos (RADAM BRASIL, 1983).

A unidade magmática é constituída de ortognaisses migmatíticos ácidos a básicos, com ortognaisses de estrutura tonalítica subordinados. Nessa unidade também podem ser encontrados outros tipos de granulitos gnaissificados, com composições variando entre gabros, dioritos, tonalitos e granodioritos. A unidade metassedimentar, em maior quantidade na área de pesquisa, é composta principalmente por paragnaisses de estrutura migmatítica, de composição pelítica e semipelítica (RADAM BRASIL, 1983; CODEMIG, 2013). Há também a presença de rochas metamórficas subordinadas, como quartzito, anfibolito, mármore, biotita-xisto e predomínio de rochas calcissilicáticas em zonas onde o metamorfismo se deu com menor intensidade. 
Os gnaisses do Complexo Juiz de Fora distribuem-se quase uniformemente por todos os compartimentos da bacia, incluindo as escarpas íngremes da serra do Brigadeiro, o vale central do rio Glória, onde se concentram os falhamentos mais expressivos da zona de cisalhamento Cataguases, e os planaltos a norte da bacia, sendo que nestes últimos o complexo possui intercalações de corpos plutônicos e coberturas arenosas depositadas pelos rios. Nas partes mais baixas da bacia, as rochas metamórficas cedem lugar a suítes intrusivas de idades semelhantes, compostas principalmente por granitos, charnoquitos, leucogranitos e migmatitos. Estas unidades plutônicas estão também associadas à unidade geomorfológica Depressão Escalonada dos rios Pomba-Muriaé (RADAM BRASIL, 1983), estando mais expostas ao regime climático do que as rochas metamórficas do alto rio Glória.

Os Latossolos Vermelho-Amarelos predominam nos planaltos da bacia, indicando acentuado intemperismo e solos muito alterados e profundos no alto rio Glória. Nos divisores topográficos, em áreas de erosão mais ativa, observa-se a existência de solos mais rasos e pouco desenvolvidos (FEAM, 2010).

\section{Base de dados e processamentos}

O processamento dos dados espaciais utilizados nesta pesquisa foi realizado no software de Sistema de Informação Geográfica ArcGIS 10.1®. O Modelo Digital de Elevação Hidrologicamente Consistente (MDEHC) foi confeccionado a partir de cartas planialtimétricas com curvas de nível com equidistância de $20 \mathrm{~m}$, pontos cotados e hidrografia em escala de 1:50.000 (IBGE, 1979).

A consistência dos dados foi previamente checada e, eventualmente corrigida, conforme os procedimentos recomendados por Camargo (2012). Posteriormente foi realizada a eliminação das depressões espúrias do MDEHC, garantindo consistência hidrológica ao modelo (Cardoso et al., 2006; Tonello et al., 2006). O MDEHC foi gerado com resolução espacial de $10 \mathrm{~m}$. A partir do MDEHC foram extraídas a declividade do terreno, reclassificada de acordo com Embrapa (1979), o modelo de orientação das vertentes e o modelo de sombreamento do relevo (Santos, 2001). Foram obtidos a área, o perímetro e o comprimento do eixo da bacia. Foram mensurados o número de canais por ordem, de acordo com o sistema de hierarquia fluvial desenvolvida por Strahler (1957). Também foram adquiridos o comprimento total dos canais da BHRG, o comprimento e a distância vetorial do canal principal (Christofoletti, 1980).

A partir desses dados, associando-os eventualmente às informações altimétricas adquiridas com o MDEHC, foram calculados os seguintes parâmetros morfométricos: relação de bifurcação (Rb); índice de sinuosidade (Is); gradiente dos canais (Gc); fator de assimetria (Af); densidade de drenagem (Dd); coeficiente de manutenção $(\mathbf{C m})$; extensão do percurso superficial (Eps); textura topográfica (Tt); índice de circularidade (Ic); amplitude altimétrica $(\mathbf{H m})$; declividade média $(\mathbf{S m})$; relação de relevo (Rr) e índice de rugosidade (Ir).

A Rb indica quantos canais de uma determinada ordem são necessários para o desenvolvimento de um canal da ordem seguinte (Clowers e Comfort, 1987). Apesar de ser um parâmetro altamente estável, varia de acordo com o controle estrutural, com altos valores de $\mathbf{R b}$ indicando o condicionamento da estrutura geológica na rede de drenagem (Strahler, 1952). O Is indica se um canal possui tendência de ser mais sinuoso ou retilíneo. Segundo Alves e Castro (2003), a sinuosidade dos canais é influenciada pela carga de sedimentos, pela compartimentação litológica, estruturação geológica e pela declividade dos canais.

O Gc tem como finalidade indicar a declividade do curso d'água, sendo um parâmetro importante para a avaliação da velocidade das águas do canal e do seu potencial erosivo. O Af indica o deslocamento lateral ou basculamento do canal fluvial em relação à área drenada. Pode estar relacionado à mudança de inclinação do terreno resultante de atividade tectônica ou por erosão diferencial de controle estrutural litológico (Couto et al., 2013).

A Dd retrata a eficiência da rede de drenagem e a disponibilidade de canais para o transporte de materiais detríticos, além do grau de dissecação do relevo resultante da atuação da rede de drenagem (Teodoro et al., 2007). De acordo com Pissarra et al. (2004), o Cm diminui à medida que o relevo se torna mais ondulado. Sendo inverso à densidade de drenagem, o $\mathbf{C m}$ possui valores baixos em bacias mais dissecadas, onde a alta declividade fornece condições mais favoráveis para a formação dos 
canais (Gomes, 2012), o que se expressa em uma menor área necessária para a manutenção dos cursos d'água.

A Eps representa a distância média percorrida pelas enxurradas entre o interflúvio e o canal permanente, sendo útil para indicar o espaçamento entre estes componentes, assim como a Tt (Christofoletti, 1980; Collares, 2000). O Ic é um indicativo do formato da bacia, sendo que quanto mais alongada maior é o favorecimento do escoamento e menor a ocorrência de cheias.

A $\mathbf{H m}$ e a $\mathbf{S m}$ são os principais fatores de influência da velocidade do escoamento superficial, uma vez que contribuem para a conversão da energia potencial do escoamento em energia cinética, influenciando diretamente na erosão por parte dos canais. A Rr indica o desnível entre a cabeceira e a foz de uma bacia, enquanto o Ir indica a rugosidade da superfície, sendo ambos importantes na análise da dissecação do relevo.

$O$ Índice de Concentração da Rugosidade (ICR) foi gerado a partir do estimador de densidade de Kernel (Câmara e Carvalho, 2001). O ICR indica a variação da declividade por unidade de área, fornecendo o padrão espacial regional da dissecação do relevo (Sampaio e Augustin, 2014). Para a aplicação do Kernel, a declividade extraída do MDEHC foi convertida para o formato vetorial pontual, conforme recomendado por Souza e Sampaio (2010). Foram executados vários testes para se definir qual seria o tamanho do raio mais apropriado para a definição da rugosidade do relevo da BHRG. Testes preliminares e estudos anteriores indicaram um valor de raio ótimo igual a $1128 \mathrm{~m}$, equivalente a aproximadamente quatro $\mathrm{km}^{2}$ de área (Sampaio, 2008). O ICR foi normalizado através de uma operação de álgebra de mapas, dividindo-se a matriz resultante da aplicação do Kernel pelo número de pixels computados. Os valores resultantes do Kernel são sempre relativos a um $\mathrm{km}^{2}$, e como foi utilizado um MDE de $10 \mathrm{~m}$ de resolução espacial, os valores do ICR foram divididos por 10000, que é o número de pixels abrangidos pelo raio de busca.

O Îndice Stream-Lenght Gradient Index (Índice SL), também definido por Etchebehere et al. (2004) como Relação DeclividadeExtensão (RDE), é calculado como o produto da multiplicação entre a declividade de um trecho de um canal e a projeção horizontal do ponto até onde está sendo calculado o índice até a cabeceira da drenagem (Hack, 1973; Souza et al., 2011). Para esta pesquisa, aderiu-se a decisão de selecionar apenas os maiores canais para a aplicação do Índice SL, com comprimento superior a $20 \mathrm{~km}$. Adotou-se como critério inicial para a definição dos segmentos analisados os pontos de interseção das curvas de nível de equidistância de $20 \mathrm{~m}$ com a rede de drenagem, como sugerido em Etchebehere et al. (2006). Para completar a subdivisão dos segmentos, em setores muito declivosos, com as isolinhas das curvas de nível muito próximas uma da outra, optou-se por unir os segmentos com tamanho inferior à $700 \mathrm{~m}$ em todos os canais trabalhados, valor este escolhido arbitrariamente de acordo com os objetivos presentes nesta pesquisa. Seguiu-se a sugestão de Hack (1973) e os primeiros $800 \mathrm{~m}$ dos canais fluviais em relação à sua nascente foram desconsiderados para fins desta análise.

Foram desconsiderados os trechos cujos gradientes estavam associados à presença de barragens de pequenas centrais hidrelétricas no baixo curso do rio Glória, com o objetivo de adquirir valores de anomalias apenas naturais, mantendo a consistência interpretativa do índice. Assim, foram selecionados ao todo 88 segmentos para o cálculo do Índice SL, com amplitude altimétrica igual ou superior à $20 \mathrm{~m}$ e com comprimentos variados. Ao final, foi calculado o Índice SL total para todos os principais canais, como proposto por McKeown et al. (1988), e os valores SL dos segmentos foram relacionados com os valores SL totais dos canais fluviais que englobam cada segmento, buscando o grau de intensidade de cada anomalia identificada, segundo metodologia desenvolvida por Seeber e Gornitz (1983).

Por fim, foram analisadas imagens orbitais de alta resolução espacial disponibilizadas gratuitamente na plataforma do software Google Earth Pro, com o objetivo de verificar a correspondência dos valores do ÍCR e do Índice SL com as feições identificadas nos canais da BHRG.

\section{Resultados}

As maiores cotas altimétricas foram registradas na serra da Providência $(1.985 \mathrm{~m}) \mathrm{e}$ na serra do Brigadeiro $(1.100 \mathrm{~m})$, divisores topográficos da BHRG (Figura 2a). Os planaltos localizados no sopé das serras apresentam valores de altitude variando de 1.100 a $650 \mathrm{~m}$, enquanto as partes associadas ao canal principal da bacia registram os menores 
valores de altitude (entre 180 e $450 \mathrm{~m}$ ), englobando o médio e o baixo rio Glória.
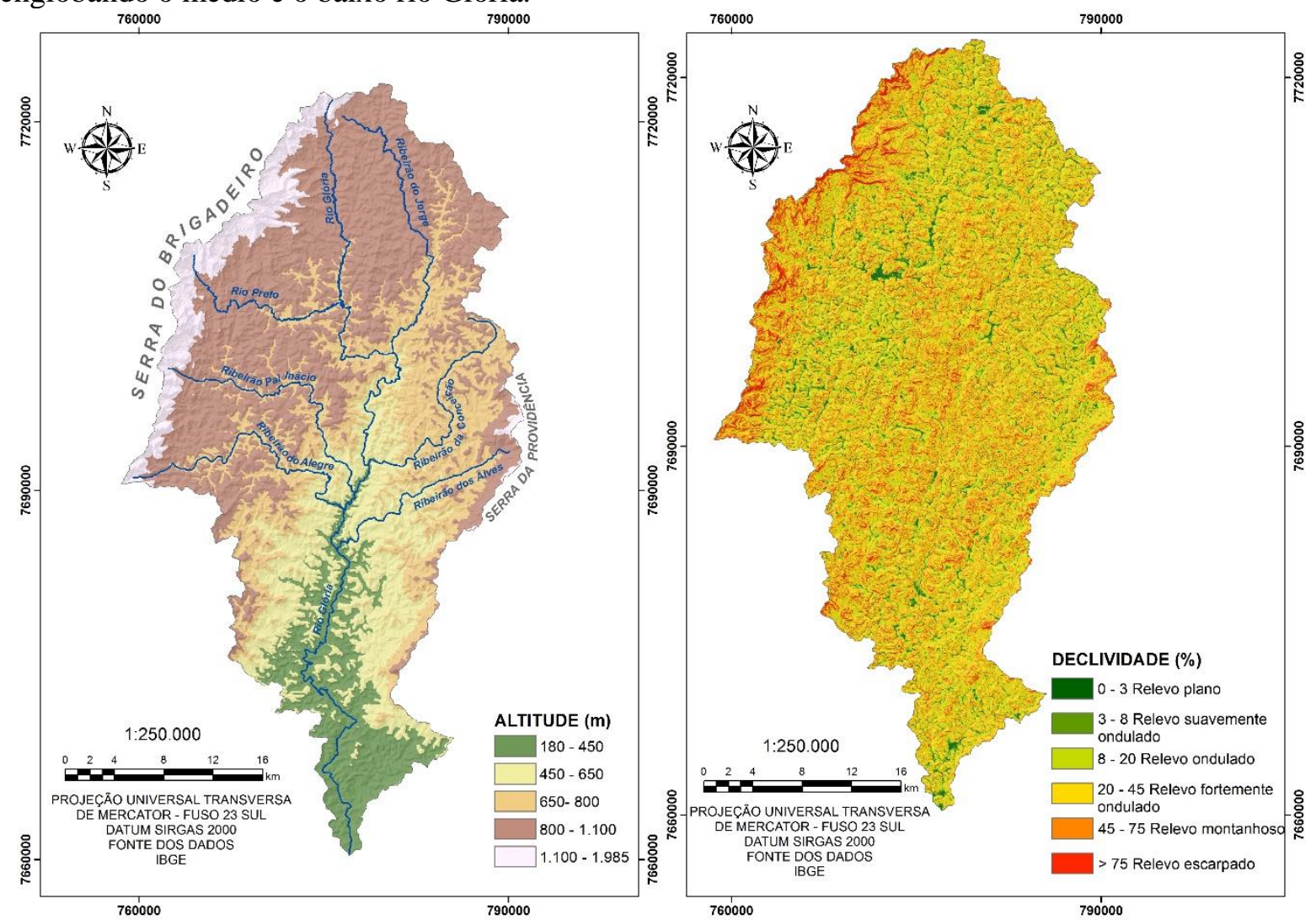

Figura 2. (a) Altitude e (b) declividade da bacia hidrográfica do rio Glória.

Aproximadamente $42 \%$ da área total da BHRG apresenta relevo fortemente ondulado (Figura 2b). Além de serem encontradas nas regiões serranas, as classes de declividade mais elevada, referentes aos relevos montanhoso e escarpado, também são observadas no médio rio Glória. As porções com os menores valores de declividade foram identificadas nos planaltos e no baixo vale do rio Glória, principalmente nas planícies de inundação associadas a trechos meândricos do rio Glória e de seus principais afluentes.

As vertentes da BHRG têm a sua orientação com dominância Leste-Oeste (Figura 3a), com $31 \%$ da área total, com relevância para as escarpas da serra do Brigadeiro. Logo em seguida vem a orientação para a direção Oeste, equivalente a $30 \%$ do terreno. Esta configuração indica um alinhamento preferencial Norte-Sul das elevações, o que indica o aspecto longitudinal do terreno, com os vales se desenvolvendo de acordo com os lineamentos associados à Zona de Cisalhamento Cataguases, com destaque para as vertentes da porção central da BHRG.

A BHRG possui formato alongado de acordo com o Ic, indicando reduzida susceptibilidade a enchentes (Tabela 1), uma vez que seu valor é inferior a 0,50 (Villela e Mattos, 1985; Romanovisk, 2001). O Ir indicou a presença de vertentes longas e íngremes, além de acentuada amplitude altimétrica entre os fundos de vale e os topos dos interflúvios. A Rr de $28,73 \mathrm{~m} / \mathrm{km}$ está associada ao grande desnível entre a cabeceira e a foz da bacia, sendo particularmente importante para este valor a presença da serra do Brigadeiro como divisor topográfico. A Eps e a Tt indicam vales amplos na BHRG, com acentuado grau de entalhamento. 

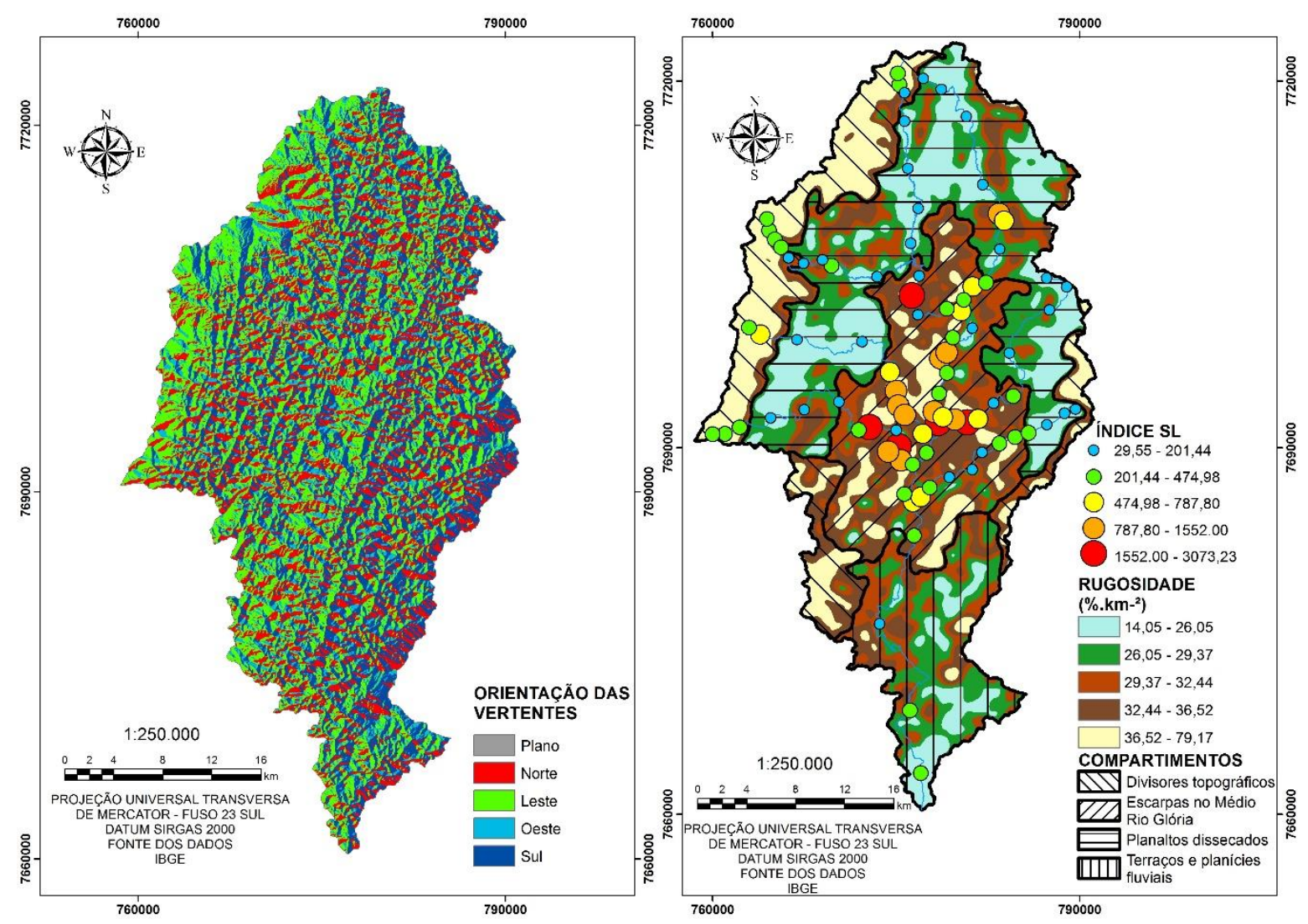

Figura 3. (a) Orientação das vertentes e (b) Índice de Concentração da Rugosidade e Índice StreamLenght Gradient da bacia hidrográfica do rio Glória.

O Is indicou que o canal é sinuoso, porém contendo trechos meândricos, identificados no alto rio Glória, onde o canal corre sobre planaltos com baixa declividade, e trechos retilíneos, como no médio rio Glória, onde o canal se desenvolve em consonância com as principais zonas de cisalhamento da BHRG (Tabela 1). O Gc também indicou declividade moderada, com os diferentes compartimentos do relevo influenciando o potencial energético do rio Glória, como é o caso das zonas de maior movimentação tectônica na faixa central da bacia. O Af indica que apesar do intenso tectonismo, o canal do rio Glória não apresenta basculamento, nem para a direita e nem para a esquerda (Tabela 1).

Os elevados valores de $\mathbf{H m}$ e $\mathbf{C m}$ indicam aprofundamento dos vales e intensa dissecação do relevo. (Tabela 1) (Crepani et al., 2001). A declividade média de $31 \%$ confirma o alto potencial de dissecação da área de estudo, com predominância do relevo fortemente ondulado na BHRG. A baixa densidade de drenagem apresentada pela BHRG é atribuída à predominância de Latossolos, solos muito espessos e porosos, e também de rochas gnáissicas porfiríticas de intenso fraturamento devido ao intemperismo, o que favorece a infiltração profunda e diminui os fluxos superficiais (Tabela 1).

Tabela 1. Parâmetros morfométricos calculados para o canal principal, área e relevo da bacia hidrográfica do rio Glória.

\begin{tabular}{cc}
\hline Parâmetros & \\
\hline Índice de sinuosidade & 1,68 \\
Gradiente dos canais (\%) & 1,17 \\
Fator de assimetria (\%) & 49,5 \\
Densidade de drenagem $\left(\mathrm{km} \cdot \mathrm{km}^{-2}\right)$ & 2,18 \\
Coeficiente de manutenção $\left(\mathrm{m}^{-2} \cdot \mathrm{m}^{-1}\right)$ & 459,16 \\
Extensão do percurso superficial $(\mathrm{m})$ & 229,36 \\
Textura topográfica $(\mathrm{km})$ & 3,95 \\
Índice de circularidade & 0,3 \\
Amplitude altimétrica $(\mathrm{m})$ & 1805,23
\end{tabular}

Siqueira, R. G., Souza, J. J. L. L., Faria, A. L. L., Fernandes Filho, E. I. 


\begin{tabular}{cc} 
Declividade média $(\%)$ & 31 \\
Relação de relevo $(\mathrm{m} / \mathrm{km})$ & 28,73 \\
Índice de rugosidade & 3935,4 \\
\hline
\end{tabular}

Utilizando-se da ordenação proposta por Strahler (1957), foram encontradas ao todo 6 ordens fluviais na BHRG. Os valores de $\mathbf{R b}$ indicam variação do padrão de bifurcação entre as ordens 5 e 6 , em comparação às ordens anteriores (Tabela 2).

Tabela 2. Relação de bifurcação das ordens fluviais da bacia hidrográfica do rio Glória.

\begin{tabular}{cc}
\hline Ordens fluviais & Relação de bifurcação \\
\hline $1 \% 2^{\circ}$ ordens & 4,38 \\
$2 \% 3^{\circ}$ ordens & 4,56 \\
$3 / 4^{\circ}$ ordens & 3,78 \\
$4 \% 5^{\circ}$ ordens & 3,86 \\
$5 \% 6^{\circ}$ ordens & 7 \\
\hline
\end{tabular}

Quatro compartimentos geomorfológicos, com diferentes níveis de dissecação, foram identificados através do Índice de Concentração da Rugosidade e do Índice Stream-Lenght Gradient (Índice SL) (Figura 3b): i) divisores topográficos, com os valores mais elevados de rugosidade e baixos valores de Índice SL. Essas áreas coincidem com as áreas de maior declividade, com maior ocorrência de cursos d'água de primeira ordem, ocorrência de Cambissolos, Neossolos Litólicos e afloramentos rochosos, onde é exposto o embasamento charnoquítico; ii) porção média do rio Glória, com valores elevados de rugosidade e de Índice SL. Esse compartimento ocorre em escarpas de falha com cursos d'água de diversas ordens; iii) planaltos dissecados soerguidos com valores de rugosidade dominantemente abaixo de $26 \% \cdot \mathrm{km}^{-2} \mathrm{e}$ os mais baixos valores de Índice SL. O terceiro compartimento ocorre em morros mamelonizados com topos rebaixados e simétricos, onde há o predomínio de Latossolos Vermelho-Amarelos, e; iv) terraços e planícies aluviais próximas da foz do rio, com baixos valores de rugosidade e de Índice SL.
Os elevados valores de Índice SL do rio Glória e dos ribeirões Alegre e Pai Inácio são atribuídos à amplitude altimétrica desses canais. (Tabela 3). Esses cursos d'água também apresentaram a maior ocorrência de anomalias de $2^{\mathrm{a}}$ ordem (Figura 4).

Tabela 3. Índice SL total para o rio Glória e seus principais afluentes.

\begin{tabular}{cc}
\hline Bacias hidrográfica & Índice SL total \\
\hline Rio Glória & 258,59 \\
Ribeirão da Conceição & 114,58 \\
Ribeirão do Alegre & 228,24 \\
Ribeirão do Jorge & 85,95 \\
Ribeirão dos Alves & 164,02 \\
Ribeirão Pai Inácio & 229,4 \\
Rio Preto & 153,43 \\
\hline
\end{tabular}

Os afluentes da margem leste do rio Glória (Figura 4a) correm por grandes distâncias com baixa variação altimétrica, indicando que encontraram o nível de base regional. Verifica-se, entretanto, que nos trechos inferiores dos cursos a declividade aumenta em concomitância às principais anomalias neotectônicas, como é o que acontece com o ribeirão da Conceição, que adquire um perfil convexo relacionado ao desequilíbrio do canal em seu trecho inferior. Por sua vez, os afluentes da margem oeste (Figura 4b) apresentam amplitudes altimétricas mais elevadas, graças à região escarpada da serra do Brigadeiro. Com exceção do rio Preto, que apresenta apenas uma anomalia e perfil côncavo, indicando a melhor condição de equilíbrio entre os canais analisados, os rios da margem oeste também correm por grandes distâncias sobre o nível de base regional, mas registram maior ocorrência de quebras de relevo. No geral, os afluentes são diretamente influenciados pela grande concentração de falhas e lineamentos estruturais que afetam a porção central da BHRG, que é expressa através da existência de anomalias contínuas no médio vale do rio Glória (Figura 4c). 

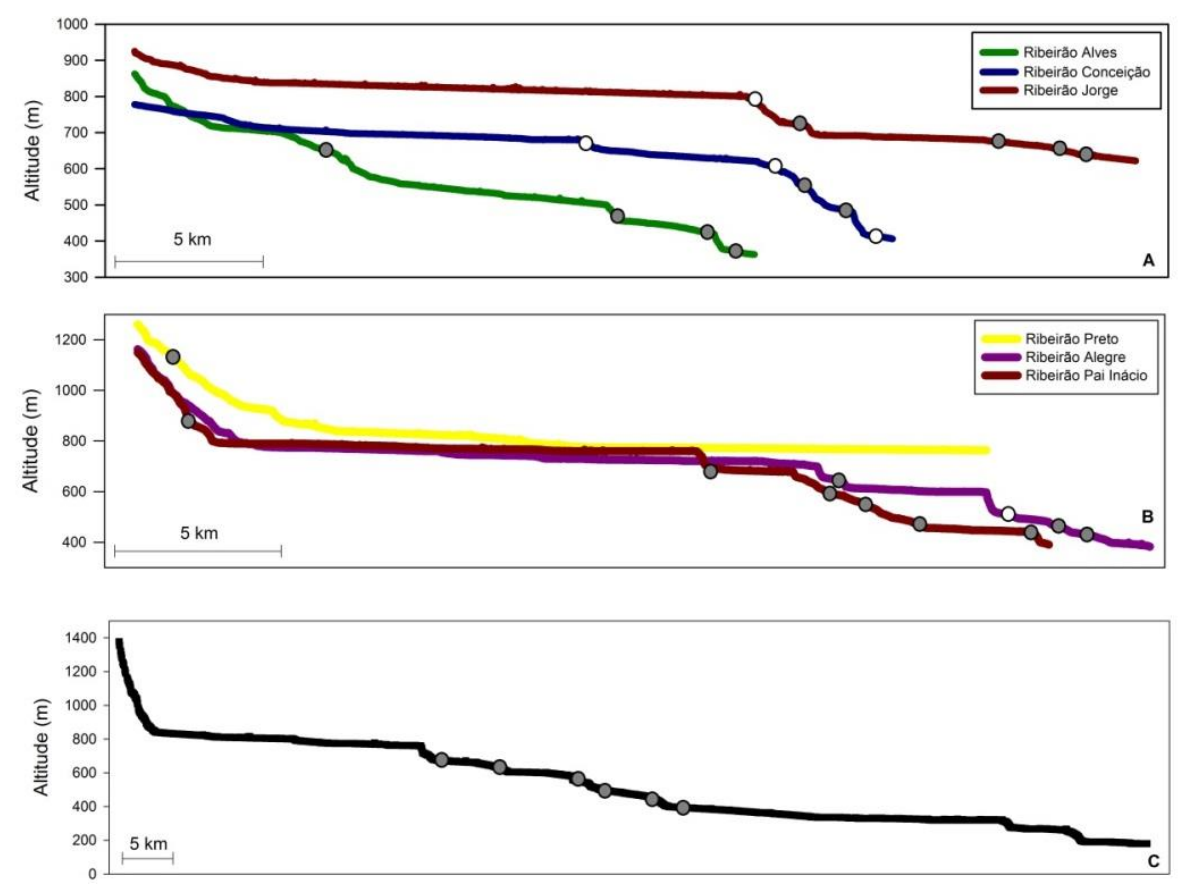

Figura 4. Perfil longitudinal e anomalias identificadas através do Índice SL dos afluentes da margem leste (a); oeste (b); e no rio Glória (c). Pontos brancos são anomalias de $1^{\circ}$ ordem e os pontos cinzas são anomalias de $2^{\mathrm{a}}$ ordem.

\section{Discussão}

As informações morfométricas que apresentaram os resultados mais relevantes para a compartimentação geomorfológica da BHRG foram: a relação de bifurcação, o Índice de Concentração da Rugosidade (ICR) e o Índice Stream-Lenght Gradient (Índice SL). Esta compartimentação é embasada nos diferentes padrões de controle da drenagem apontados por estes dados, influenciada principalmente pelo acentuado controle estrutural.

$\mathrm{O}$ valor da relação de bifurcação entre as maiores ordens da área de pesquisa (5 e 6) é quase três vezes mais alto em comparação com o registrado entre ordens máximas em regiões de clima temperado (Clowes e Comfort, 1987) e tropical (Christofoletti, 1980; Fonseca, 2010), indicando profunda dissecação. Tal dissecação pode ser atribuída à variação de resistência das rochas à meteorização ou, como parece ser o caso, ao controle estrutural exercido pelas zonas de cisalhamento no talvegue principal do rio Glória (Horton, 1945). Esta constatação pode ser embasada através da observação da homogeneidade dos grupos litológicos da BHRG, com predominância de rochas gnáissicas com graus de resistência semelhantes à ação fluvial (Figura 1b). A relação de bifurcação não variou de acordo com o comportamento hidrológico dos solos da
BHRG, em oposição a estudos anteriores em outras áreas (França, 1968).

$O$ Índice de Concentração da Rugosidade, apesar de distribuído de forma heterogênea pelos diferentes compartimentos geomorfológicos da área de pesquisa, indica que a BHRG apresenta elevada dissecação do relevo em toda a sua extensão. A bacia apresenta valores mínimos de ICR que classificam o relevo como fortemente ondulado (Sampaio e Augustin, 2008).

Os compartimentos com maiores valores de ICR distinguem-se pelo Índice SL (Figura 4b). Os altos valores de ICR e baixos Índice SL, nas escarpas e cristas assimétricas que formam os divisores topográficos da bacia, indicam que o relevo é fortemente marcado pela dissecação diferencial, com o entalhamento dos talvegues podendo alcançar de 268 a $344 \mathrm{~m}$ de profundidade (RADAM BRASIL, 1983). Nestas áreas, os vales são alinhados, com presença de blocos fraturados nas encostas, formando pontões elevados quando a dissecação é mais acentuada. Os canais fluviais, de baixa profundidade e muito alimentados pelas águas superficiais provenientes das precipitações locais da serra do Brigadeiro, correm em meio aos pontões e cristas em vales encaixados que cortam os principais lineamentos estruturais SSO-NNE (Figura 1b), criando padrões paralelos da drenagem devido 
ao elevado nível de base. Há a também a formação de colúvios no sopé das escarpas, onde os solos são mais profundos (SEMAD, 2007).

Os elevados ICR e Índice SL na porção do médio rio Glória são atribuídos a características estruturais da BHRG. Grande parte dos altos valores do Índice SL está relacionada a áreas de litologia homogênea (Figura 1b) e aos padrões de drenagem treliça e retangular, fato que reafirma a influência tectônica no setor intermediário da BHRG. Desta forma, é na região do médio rio Glória que são encontrados os principais knickpoints regionais da BHRG, que interferem significativamente no equilíbrio dinâmico dos perfis longitudinais dos rios à jusante e a montante dessas rupturas. Pertencendo a estágios cíclicos diferentes, os segmentos à jusante adquirem características categorizadas como jovens, enquanto aqueles à montante passam a apresentar aspectos mais desenvolvidos, ou categorizados como senis e maduros (Christofoletti, 1981). Na BHRG, esta situação pode ser observada tanto no rio Glória, como nos afluentes com presença de anomalias neotectônicas no seu baixo curso. Enquanto os trechos fluviais à jusante dos principais knickpoints apresentam fluxo mais turbulento, com presença de corredeiras e cachoeiras (Figura 5), os trechos à montante dos knickpoints, localizados nos planaltos dissecados, adquirem menor potencial de transporte de sedimentos e de dissecação do relevo, uma vez que as rupturas passam a funcionar como o novo nível de base local destes trechos.

O compartimento dos extensos planaltos dissecados da BHRG com baixos valores de ICR e Índice SL apresentaram um padrão de dissecação homogêneo, com maior influência climática na modelagem do relevo e entalhamento do talvegue menos profundo, podendo variar de 87 a $104 \mathrm{~m}$ de profundidade (RADAM BRASIL, 1983). Marcados pela presença de solos profundos drenados por canais de ordens intermediárias, com destaque para os Latossolos Vermelho-Amarelos, esse compartimento é caracterizado pelo fraco potencial gravitacional da água nestas áreas, devido à baixa declividade. Esta condição induz à deposição local dos sedimentos erodidos das partes mais altas nos planaltos da porção oeste, criando depósitos aluvionares arenosos nas calhas dos rios que contribuem para o aumento do comprimento dos canais a partir da formação de meandros não encaixados.

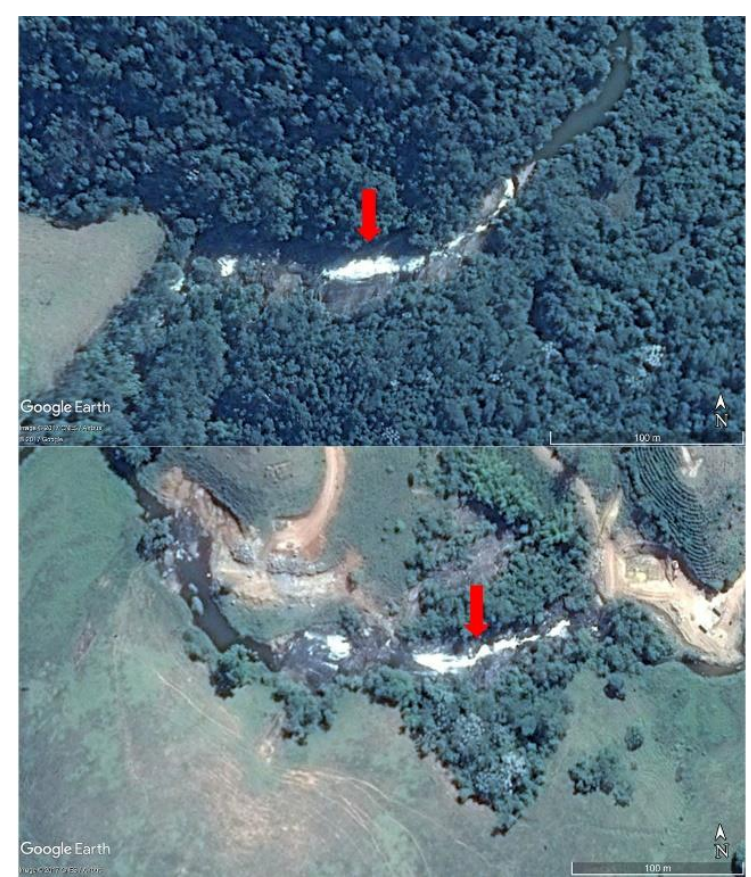

Figura 5 Presença de knickpoints em trechos fluviais nas Escarpas do médio rio Glória, associados a altos valores do Índice SL. Rio Glória - SL 2031,48 (acima) e ribeirão do Alegre - SL 2111,66 (abaixo) (Fonte: Google Earth Pro)

Apesar da presença de grandes lineamentos estruturais nos planaltos dissecados, o que é refletido em canais com padrão treliça ou retangular em alguns setores deste compartimento, verifica-se que as interferências neotectônicas não produziram o rejuvenescimento dos planaltos com a mesma intensidade que nas áreas centrais. Desta forma, os vales destas áreas se encontram em processo evolutivo mais avançado, com o alargamento das vertentes associadas ao desenvolvimento de planícies de inundação e terraços mais extensos. Alguns canais encontram-se também anastomosados (Figura 6), possuindo inclusive meandros abandonados, devido à grande quantidade de material grosseiro transportado de regiões mais altas, principalmente da serra do Brigadeiro, e que devido à baixa potência dos rios, são depositados no próprio leito. $\mathrm{O}$ obstáculo natural que então se forma, pela rugosidade e saliências, faz com que o rio se ramifique em múltiplos canais, pequenos e rasos, e desordenados devido às constantes migrações entre ilhotas (Christofoletti, 1981). Nas áreas mais baixas da bacia, próximo à foz 
do rio Glória, a baixa dissecação do relevo é atribuída não somente ao reduzido gradiente dos rios, mas também ao embasamento granítico das suítes intrusivas (Figura 1b), mais resistente à erosão mecânica dos canais. Formam-se terraços e planícies aluviais onde ocorrem Latossolos Vermelho-Amarelos e Argissolos Vermelho-Amarelos.

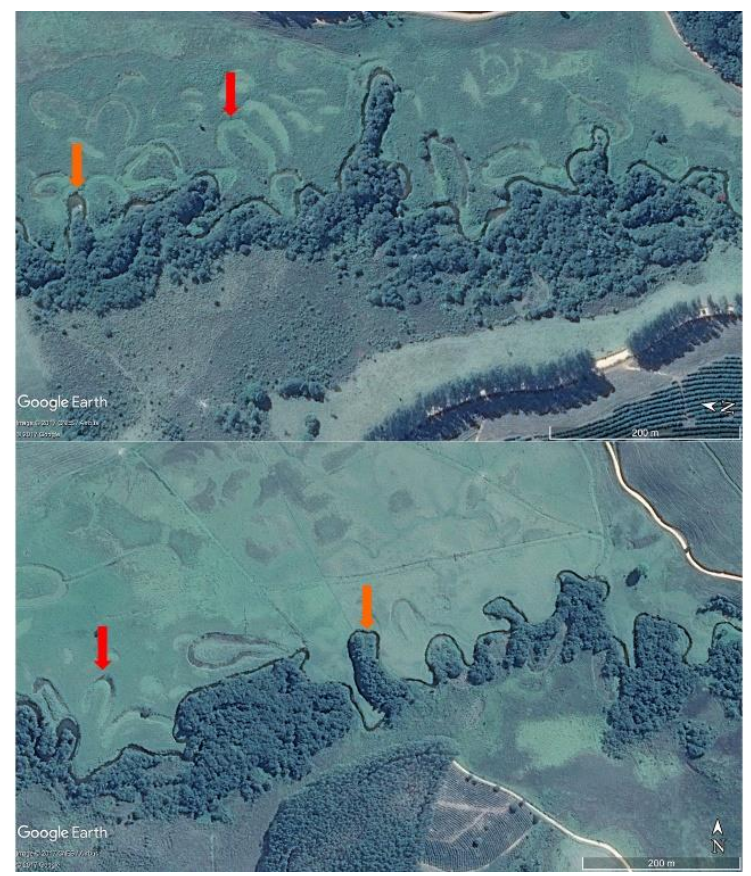

Figura 6 Presença de trechos fluviais

anastomosados (setas laranjas), com presença de meandros abandonados (setas vermelhas), localizados nos planaltos dissecados da Bacia

Hidrográfica do rio Glória e associados a baixos valores do Índice SL. Rio Glória - SL 32,92 (acima) e rio Preto - SL 58,68 (abaixo) (Fonte: Google Earth Pro)

A interação entre os agentes morfoclimáticos e os processos tectônicos na conformação do relevo pode ser observada pelos valores do ICR. O controle estrutural sobre a rede de drenagem garantiu valores de índices de dissecação da BHRG até duas vezes mais altos do que os registrados em áreas de litologia mais tenra, como em sistemas cársticos no estado do Paraná (Nascimento et al., 2010; Missura, 2013; Lima, 2013). Por sua vez, a contribuição dos agentes erosivos na esculturação do relevo na BHRG revela-se pelos valores até dez vezes mais altos de ICR em comparação com áreas que também sofreram importantes interferências tectônicas, mas que possuem clima mais seco, como a Faixa de Dobramentos Sergipana no nordeste brasileiro (Bastos Júnior et al., 2015). Valores similares de ICR da BHRG em relação à outras áreas do Escudo oriental brasileiro são atribuídos à história tectônica semelhante e às condições climáticas que favorecem a dissecação em todas estas regiões (Sampaio, 2008; Sampaio e Augustin, 2014).

Apesar da conhecida eficiência do Índice SL na detecção de deformações neotectônicas no sistema de drenagem, o mesmo também sofre influência da litologia e agentes morfoclimáticos. Estudos realizados em áreas de rochas mais tenras ao intemperismo indicam valores de Índice SL menores do que os observados em rochas mais resistentes e até 2,5 vezes menores do que o Índice SL total da BHRG (Etchebehere et al., 2004; Troiani e Della seta, 2008; Celarino e Ladeira, 2014). Por outro lado, Monteiro et al. (2010) registrou para a Bacia Tracunhaém (PE), em litologia semelhante, mas clima menos chuvoso, valores de Índice SL até quatro vezes mais baixos do que os calculados para a BHRG. Por sua vez, Fonseca (2010) encontra anomalias mais significativas na serra do Espinhaço Meridional, em Minas Gerais, principalmente na bacia do Alto Jequitinhonha, onde os maiores valores do Índice SL total encontram-se na faixa de 412 a 793. Como a composição litológica e o regime pluviométrico dessa área é semelhante às características da BHRG, toma-se que os maiores valores do índice na bacia do Alto Jequitinhonha estão associados à um tectonismo mais intenso do que na BHRG.

\section{Conclusão}

complexidade geomorfológica, com identificação de importantes compartimentos do relevo regional, como escarpas e planaltos, associados com o potencial de dissecação dos cursos fluviais em cada área. A rede hidrográfica da BHRG indicou evolução condicionada por litoestruturas tectônicas do Pré-Cambriano, com acentuada interferência das reativações do Mesozoico-Cenozoico, que por sua vez apresentam influência diversificada na área de pesquisa. O ICR e o Índice SL foram similares entre ambientes de clima, história tectônica e litologias semelhantes, e discrepantes entre áreas de clima ou resistência da rocha à meteorização diferentes.

O estudo da influência tectônica e climática sobre a dissecação do relevo da BHRG tem como intenção contribuir para

Siqueira, R. G., Souza, J. J. L. L., Faria, A. L. L., Fernandes Filho, E. I. 
futuras pesquisas sobre a evolução paleogeográfica recente dos falhamentos no Sudeste brasileiro, tendo as bacias hidrográficas como unidades fundamentais para a aplicação geomorfológica. Buscou-se também que a pesquisa em questão possa contribuir para futuros trabalhos que envolvam como metodologia a análise morfométrica de bacias hidrográficas, através do fornecimento de um extenso compilado de parâmetros selecionados na literatura acadêmica existente, seja para a aplicação de estudos morfoestruturais ou de outro gênero.

A aplicação dos parâmetros morfométricos a partir de técnicas e procedimentos em ambiente SIG apresentou resultados satisfatórios para o entendimento do comportamento do relevo na BHRG. Entretanto, é necessário ressaltar a importância da complementação e validação em campo posterior de todas as informações adquiridas laboratorialmente.

\section{Agradecimentos}

Os autores agradecem ao Centro de Estudos e Desenvolvimento Florestal do Instituto Estadual de Florestas de Minas Gerais (CEDEF/IEF) pela disponibilidade da base cartográfica e da infraestrutura e equipamentos necessários para a realização deste trabalho.

\section{Referências}

Ab'saber, A. N, 2003. Os Domínios de Natureza no Brasil: potencialidades paisagísticas. 4. ed. Ateliê Editorial, São Paulo.

Almeida, F. F. M.; Carneiro, C. D, 1998. Origem e evolução da serra do Mar. Revista Brasileira de Geociências 28, 135-150.

Alves, J.M.P; Castro, P.T.A., 2003. Influência de feições geológicas na morfologia da bacia do rio do Tanque (MG) baseada no estudo de parâmetros morfométricos e análises de padrões de lineamentos. Revista Brasileira de Geociências 33, 117- 124.

Bastos Júnior, E. M. B.; Siqueira, J.; Almeida, J. A. P., 2015. Aplicação do Índice de Concentração de Rugosidade (ICR) em uma região de pediplano sertanejo no semiárido nordestino, Nossa Senhora da Glória/SE. In: Simpósio Brasileiro de Sensoriamento Remoto, 17, João Pessoa, Brasil. Anais...INPE, São José dos Campos, pp. 6030-6034.
Câmara, G.; Carvalho, M. S., 2004. Análise de Eventos Pontuais, in: Druck, S.; Carvalho, M. S.; Câmara, G.; Monteiro, A. V. M (Eds.). Análise Espacial de Dados Geográficos. EMBRAPA, Brasília, pp. 2742.

Camargo, R. A., 2012. Avaliação da susceptibilidade à erosão e proposição de zoneamento estratégico com vistas à sustentabilidade da bacia hidrográfica do rio Piranga, MG. Dissertação (Mestrado). Viçosa, Universidade Federal de Viçosa.

Cardoso, C. A.; Dias, H. C. T.; Soares, C. P. B.; Martins, S. V, 2006. Caracterização morfométrica da bacia hidrográfica do rio Debossan, Nova Friburgo, RJ. Revista Árvore 30, 241-248.

Celarino, A. L. S; Ladeira, F. S. B., 2014. Análise morfométrica da Bacia do rio Pardo (MG e SP). Revista Brasileira de Geomorfologia 15, 471-491.

Christofoletti, A., 1980. Geomorfologia. 2. ed. Edgard Blucher, São Paulo. , 1981. Geomorfologia Fluvial v. 1. Edgard Blucher, São Paulo.

Clowes A; Comfort, P., 1987. Process and Landform: Conceptual Frameworks in Geography. Oliver \& Boyd, Londres.

CODEMIG - Companhia de Desenvolvimento Econômico de Minas Gerais, 2013. Mapa Geológico do estado de Minas Gerais. Disponível em: <http://www.portalgeologia.com.br/>. Acesso em: 25 jan. 2016.

Collares, E. G., 2000. Avaliação de alterações em redes de drenagem de microbacias como subsídio ao zoneamento geoambiental de bacias hidrográficas: Aplicação na bacia hidrográfica do rio Capivari. Tese (Doutorado). São Carlos, Escola de Engenharia, Universidade de São Paulo.

Couto, E. V.; Fortes, E.; Ferreira, J.H.D., 2013. Índices geomorfológicos aplicados a análise morfoestrutural da zona de falha do rio Alonzo - PR. Revista Brasileira de Geomorfologia 14, 287-297.

Crepani, E.; Medeiros, J. S.; Filho, P. H.; Florenzano, T. G.; Duarte, V.; Barbosa, C. C. F., 2001 Sensoriamento Remoto e Geoprocessamento aplicados ao Zoneamento Ecológico-Econômico e ao Ordenamento Territorial. INPE, São José dos Campos. 
Delgado, I.M; Souza; J.D; Silva, L.C; Filho, N.C.S; Santos, R.A; Pedreira, A.J; Guimarães, J.T; Angelim, A.A; Vasconcelos, A.M; Gomes, I.P; Filho, J.V.L; Valente, C.V; Perrotta, M.M; Heineck, C.A., 2003. Geotectônica Do Escudo Atlântico, in: Bizzi, L.A.; Schobenhaus, C.; Vidotti, R.M.; Gonçalves, J.H. (Eds.). Geologia, Tectônica e Recursos Minerais do Brasil: Textos, mapas e SIG. CPRM (Programa Levantamento de Recursos Minerais do Brasil), Brasilia, pp. 227-258.

DNPM - Departamento Nacional de Produção Mineral - Projeto RADAM BRASIL, 1983. Folhas SF 23/24 - Rio de Janeiro/Vitória, geologia, geomorfologia, pedologia vegetação e uso potencial da terra (Levantamento de Recursos Naturais, 32). Rio de Janeiro.

EMBRAPA - Empresa Brasileira de Pesquisa Agropecuária, 1989. Súmula da 10. Reunião Técnica de Levantamento de Solos. EMBRAPA-SNLCS (Serviço Nacional de Levantamento e Conservação de Solos), Rio de Janeiro.

Etchebehere, M. L.; Saad, A. R.; Fulfaro, V. J.; Perinotto, J. A. J., 2014. Aplicação do Índice Relação Declividade-Extensão - RDE na bacia do rio do Peixe (SP) para Detecção de Deformações Neotectônicas. Revista do Instituto de Geociências - USP 4, 43-56.

Etchebehere, M. L.; Saad, A. R.; Santoni, G.; Casado, F. C.; Fulfaro, V. J., 2006. Detecção de prováveis deformações neotectônicas no vale do rio do Peixe, mediante aplicação de índices RDE em segmentos de drenagem. Geociências - UNESP 25, 271-287.

FEAM, Fundação Estadual do Meio Ambiente, 2010 (meio digital). Mapa de Solos do estado de Minas Gerais. Disponível em: http://www.dps.ufv.br/?page_id=742. Acesso em: 20 de fev. 2016.

Fonseca, B. M., 2010. O uso do Sistema de Informações Geográficas na análise morfométrica e morfológica de bacias de drenagem na serra do Espinhaço Meridional, MG. Dissertação (Mestrado). Belo Horizonte, Instituto de Geociências, Universidade Federal de Minas Gerais.

Fonseca, B.M.; Augustin, C.H.R., 2014. Análise morfométrica de bacias de drenagem e sua relação com a estrutura geológica na serra do Espinhaço Meridional - MG.
Revista Brasileira de Geomorfologia 15, 153-172.

França, G. V., 1968. Interpretação fotográfica de bacias e de redes de drenagem aplicadas a solos da região de Piracicaba. Tese (Doutorado). Piracicaba, Escola Superior de Agricultura "Luiz de Queiroz", Universidade de São Paulo.

Gomes, J. B. O., 2012. Morfometria e qualidade da água em microbacias do município de Guaçuí - ES. Dissertação (Mestrado), Vitória, Universidade Federal do Espírito Santo.

Hack, J. T., 1973. Stream-profile analysis and stream gradient index. Journal of Research of the U.S. Geological Survey 1, 421-429.

Horton, R. E. Erosional development of streams and their drainage basins - Hydrophysical approach to quantitative morphology, 1945. Bulletin of the Geological Society of America 56, 275-370.

Huggett, R. J., 2007. Fundamentals of Geomorphology. Taylor \& Francis Group, New York.

IBGE - Instituto Brasileiro de Geografia e Estatística, 1979. Mapeamento Topográfico Sistemático do Brasil, escala 1:50.000 (meio digital). Rio de Janeiro. Disponível em: <http://downloads.ibge.gov.br/>. Acesso em: 15 set. 2015.

Lima, I. M. M. F., 2013. Morfodinâmica e meio ambiente na porção centro-norte do Piauí, Brasil. Tese (Doutorado). Belo Horizonte, Instituto de Geociências, Universidade Federal de Minas Gerais.

McKeown, F. A.; Jones-Cecil M.; Askew. B. L.; McGrath M. B, 1988. Analysis of streamprofile data and inferred tectonic activity, Eastern Ozark Mountains region. U. S. Geological Survey Bulletin 1807, 1-39.

Missura, R., 2013. Bacia do Riacho Pioré - PE: Análise Morfotectônica e Morfoestratigráfica. Tese (Doutorado). Recife, Universidade Federal de Pernambuco, Recife.

Monteiro, K. A; Missura, R.; Silva, H. A.; Correa. A. C. B., 2010. Aplicação do Índice de Hack - ou RDE - ao rio Tracunhaém PE. In: Congresso Argentino do Cuaternário y Geomorfologia, 4, Congresso da Associação Brasileira de Estudos do Quaternário, 12, Reunión sobre el Cuaternário de América del Sur, 2, La Plata, Argentina. Anais...ABEQUA, São Paulo, pp. $17-23$. 
Nascimento, E. R.; Neto, J. M. R.; Rebelo, A. M. A., 2010. Aplicação do Índice de Concentração da Rugosidade do relevo no entendimento do nível de exposição dos sistemas cársticos ocorrentes na região norte do município de Curitiba - PR. Revista Brasileira de Geomorfologia 11, 61-68.

Novo, E. M. L. M., 2010. Ambientes Fluviais, in: Florenzano, T. G. (Org.) Geomorfologia: Conceitos e Tecnologias Atuais. São Paulo: Oficina de Textos, São Paulo, pp. 219-232.

Pires, F. R. M., 1998. Arcabouço Geológico, in: Cunha, S. B.; Guerra, A. J. T (Org). Geomorfologia do Brasil. Bertrand Brasil, Rio de Janeiro, pp. 17-70.

Pissara, T.C.T.; Politano, W.; Ferraudo, A.S., 2004. Avaliação de características morfométricas na relação solo-superfície da bacia hidrográfica do córrego Rico, Jaboticabal (SP). Revista Brasileira de Ciência do Solo 28, 297-305.

Romanovski, Z., 2001. Morfologia e aspectos hidrológicos para fins de manejo da microbacia da Rua Nova, Viçosa-MG, para fins de manejo. Tese (Mestrado). Viçosa, Universidade Federal de Viçosa.

Sampaio, T. V. M., 2008. Parâmetros morfométricos para melhoria da acurácia do mapeamento da rede de drenagem - uma proposta baseada na análise da bacia hidrográfica do rio Benevente - ES. (Doutorado). Belo Horizonte, Instituto de Geociências, Universidade Federal de Minas Gerais.

Sampaio, T. V. M.; Augustin, C. H. R. R., 2014. Índice de Concentração da Rugosidade: Uma nova proposta metodológica para $\mathrm{o}$ mapeamento e quantificação da dissecação do relevo como subsídio à cartografia geomorfológica. Revista Brasileira de Geomorfologia 15, 47-60.

Santos, A. R., 2001. Caracterização morfológica, hidrológica e ambiental da bacia hidrográfica do rio Turvo Sujo, microregião de Viçosa, MG. Tese (Doutorado). Viçosa, Universidade Federal de Viçosa.

Seeber, L.; Gornitz, V., 1983. River profiles along the Himalayan arc as indicators of active tectonics. Tectonophysics 92, 335367.

SEMAD - Secretaria do estado de Meio Ambiente e Desenvolvimento Sustentável. Mapa da Flora Nativa e dos Reflorestamentos de Minas Gerais, 2009 (meio digital). Zoneamento Ecológico
Econômico do estado de Minas Gerais (ZEE-MG). Disponível em: < http://geosisemanet.meioambiente.mg.g ov.br/zee/>. Acesso em: 10 jan. 2016.

SEMAD - Secretaria do estado de Meio Ambiente e Desenvolvimento Sustentável, 2007. Plano de Manejo do Parque Estadual da serra do Papagaio. Disponível em: $<$ http://www.ief.mg.gov.br/areasprotegidas/gestao/1712-plano-demanejoparqueestadual-serra-dobrigadeiro> Acesso em: 15 jan. 2016.

Souza, L. F.; Sampaio, T. V. M. Aplicação do Índice de Concentração da Rugosidade à identificação de classes de dissecação do relevo: uma proposta de quantificação e automatização em ambiente SIG. In: Simpósio Brasileiro de Ciências Geodésicas e Tecnologias da Geoinformação, 3, Recife, Brasil. Anais...UFPE, Recife.

Strahler, A. N., 1952. Hypsometric (areaaltitude) analysis of erosional topography. Geological Society America Bulletin 63, 1117-1142.

Strahler, A. N., 1957. Quantitative Analysis of Watershed Geomorphology. Transactions American Geophysical Union 38, 913-920.

Teodoro, V. L. I.; Teixeira, D.; Costa, D. J. L.; Fuller, B. B., 2007. O conceito de bacia hidrográfica e a importância da caracterização morfométrica para o entendimento da dinâmica ambiental local. Revista Uniara 20, 137-154.

Tonello, K. C.; Dias, H. C. T.; Souza, A. L.; Ribeiro, C. A. A. S.; Leite, F. P., 2006. Morfometria da Bacia Hidrográfica da Cachoeira das Pombas, Guanhães - MG. Revista Árvore 30, 849-857.

Troiani F.; Della Seta M., 2008. The use of the Stream Lenght-Gradient index in morphotectonic analysis of small catchments: A case study from Central Italy. Geomorphology 102, 159-168.

Vervloet, R. J. H. M., 2009. Condicionantes morfológicos e estruturais na dinâmica fluvial da bacia hidrográfica do rio Benevente - Espírito Santo. Dissertação (Mestrado). São Paulo, Universidade de São Paulo, 2009.

Vieira, B.C.; Gramani, M.F., 2015. Serra do Mar: The Most Tormented Relief in Brazil. In: Vieira, B.C., Santos, L.J.C.; Salgado, A.A.R (Eds.). Landscapes and landforms of 
Revista Brasileira de Geografia Física v11, n.02 (2018) 532-546.

Brazil. Springer-Verlag, New York, pp. 285297.

Villela, S.M.; Mattos, A, 1975. Hidrologia aplicada. McGRAW-Hill do Brasil, São Paulo.
Wohl, E., 2014. Time and the rivers flowing: Fluvial geomorphology since 1960. Geomorphology 216, 263-282. 